\title{
Prioritising quality improvement
}

\author{
(2) $($ O $\Theta$ OPEN ACCESS \\ QI is a team sport, best played by those making the improvements
}

\author{
Joanna Bircher clinical director \\ Greater Manchester GP Excellence Programme, Manchester, UK
}

In almost every part of our lives we are inundated with information. The working lives of primary care doctors and their managers are no different. In 1964 Bertram Gross, professor of political science at Hunter College in New York, defined the concept of information overload:

"Information overload occurs when the amount of input to a system exceeds its processing capacity. Decision makers have fairly limited cognitive processing capacity. Consequently, when information overload occurs, it is likely that a reduction in decision quality will occur."

The quality of the care we provide is measured, benchmarked, and reported back to us by a multitude of organisations. In England, primary care doctors can compare their patient experience scores with those of the practice down the road through the National GP Patient Survey. ${ }^{2}$ They can see how well they are achieving screening targets on the public health websites $^{3}$ and compare their prescribing on openprescribing.net. ${ }^{4}$

Commissioning organisations send practices data on referring behaviour, rates of unplanned admissions, or how much their patients use the emergency department. Some aspects of performance can affect practice income through performance related pay, ${ }^{5}$ including targets for treatment and follow-up of patients with long term conditions. Regulators use much of this information to guide judgments of services provided. ${ }^{6}$

\section{Where to start?}

With so many possible areas where improvements might be made, it can feel like an impossible task to choose which should take priority. Improvement often needs several iterative cycles before solutions that work emerge. Sustained improvement takes time and effort, and it is easy to get demoralised if practices or individuals take on too many projects and can't follow them through. It is tempting to prioritise the areas that affect practice income or please regulators rather than projects that matter more to patients and staff.
High quality care develops when an organisational culture promotes curiosity, experimentation, and continuous small cycles of change, particularly when changes are designed and driven by the people delivering care, in full collaboration with patients. ${ }^{7}$ Quality improvement is a team sport and is played best when owned by those making the improvements. Projects work best when priorities are set locally unless external benchmarking data show problems with patient safety or quality of care or practice viability is being affected by poor performance in financially driven targets.

Primary care doctors have an important role in quality improvement. They need to be aware of practice performance data and find ways to present it to the practice team and patients in a meaningful way-for example, by taking into account variations in practice demographics and list turnover.

The increase in primary care workload without a matched increase in funding limits the time available for practice development and improvement. ${ }^{8}$ Although there has been some attempt to rectify this, until the effects are felt at the frontline, practices must prioritise improvements that focus on working more effectively and efficiently. This is in line with the NHS sustainable improvement programme Time for Care. ${ }^{9}$ Feedback from participants of the programme indicates that it has improved job satisfaction and teamwork and embedded basic quality improvement methods that practices can apply to other aspects of care such as patient outcomes and access.

Improvement won't happen unless people take action. The importance of "starting with why" has been recognised in many workplace environments, ${ }^{10}$ and healthcare delivery and improvement is no different. If people working in a practice have a strong sense of purpose and know why they do what they do, they will notice when current performance isn't delivering their aspirations. This can generate improvement priorities that resonate with the values, vision, and purpose of the team and the organisation. Using these priorities to create broad themes over time creates a coherent and meaningful improvement plan that everyone understands and can work towards. 
Competing interests: I have read and understood BMJ policy on declaration of interests and declare that I am a GP partner. Greater Manchester GP Excellence Programme is a collaboration between the Royal College of General Practitioners and Greater Manchester Health and Social Care Partnership.

Provenance and peer review: Commissioned; not externally peer reviewed.

This article is one of a series commissioned by The BMJ based on ideas generated by a joint editorial group with members from the Health Foundation and The BMJ, including a patient/carer. The $B M J$ retained full editorial control over external peer review, editing, and publication. Open access fees and The BMSs quality improvement editor post are funded by the Health Foundation.

1 Gross BM. The managing of organizations: the administrative struggle. Free Press of Glencoe, 1964.

2 NHS England, NHS Improvement. National GP patient survey. https://www.gp-patient.co. uk/

3 Public Health England. National general practice profiles. https://fingertips.phe.org.uk/ profile/general-practice
4 EBM DataLab. Open Prescribing. https://openprescribing.net

NHS Digital. Quality and outcomes framework. https://digital.nhs.uk/data-and-information/ data-collections-and-data-sets/data-collections/quality-and-outcomes-framework-qof

6 Care Quality Commission. How we monitor GP practices. https://www.cqc.org.uk/guidanceproviders/gps/how-we-monitor-gp-practices

7 Mannion R, Davies H. Understanding organisational culture for healthcare quality improvement. BMJ 2018;363:k4907. 10.1136/bmj.k4907 30487286

8 Baird B, Charles A, Honeyman M, Maguire D, Das P. Understanding pressures in general practice. Kings Fund, 2016.

9 NHS England. Releasing time for care. https://www.england.nhs.uk/gp/gpfv/redesign/ gpdp/releasing-time/

10 Sinek S. Start with why: how great leaders inspire everyone to take action. Penguin Random House, 2011.

Published by the BMJ Publishing Group Limited. For permission to use (where not already granted under a licence) please go to http://group.bmj.com/group/rights-licensing/ permissionsThis is an Open Access article distributed in accordance with the Creative Commons Attribution Non Commercial (CC BY-NC 4.0) license, which permits others to distribute, remix, adapt, build upon this work non-commercially, and license their derivative works on different terms, provided the original work is properly cited and the use is non-commercial. See: http://creativecommons.org/licenses/by-nc/4.0/. 